\title{
Rat recombinant $\beta$-defensin 22 is a heparin-binding protein with antimicrobial activity
}

\author{
Hua Diao ${ }^{1, *}$, He-Guo Yu ${ }^{1, *}$, Fei Sun ${ }^{2}$, Yong-Lian Zhang ${ }^{1,3}$ and Nongnuj Tanphaichitr ${ }^{4}$ \\ Approximately 40-50 $\beta$-defensins are predominantly expressed in the male reproductive system of mammals. This selective expression \\ raises the question as to the roles of these molecules in innate immunity and fertility in the male reproductive tract. Rat $\beta$-defensin 22 is \\ an epididymis-specific $\beta$-defensin expressed in segments 12-14 of the epididymis. This protein contains both $\beta$-defensin and lectin \\ signature sequences, yet its antimicrobial activity and carbohydrate-binding ability have not been shown. We herein demonstrated the \\ antimicrobial activity of recombinant rat $\beta$-defensin 22 against Escherichia coli and Candida albicans. Its lectin-like activity was also \\ investigated by demonstrating its binding ability with heparin beads. This heparin-binding activity implies some potential roles for this \\ defensin in determining the fertilisation capabilities of sperm.
}

Asian Journal of Andrology (2011) 13, 305-311; doi:10.1038/aja.2010.93; published online 13 December 2010

Keywords: epididymis; rat; recombinant protein; sperm

\section{INTRODUCTION}

The fully differentiated spermatozoa from the testis undergo substantial remodelling and modification to acquire sperm motility and fertilizing capacity during passage through the epididymal duct. ${ }^{1}$ The sperm plasma membrane is the most important entity that directly interacts with the luminal fluid of the reproductive tract, as well as the egg surface. A number of $\beta$-defensin-like proteins have been found in the epididymis. Various peptides of the $\beta$-defensin family are involved in and mediate various biological processes based on their pleiotropic activities. ${ }^{2-9} \mathrm{~A}$ number of these processes are beyond immune-related events; these include cell differentiation, tumour development, tissue remodelling ${ }^{10}$ and sperm maturation. ${ }^{11}$ Nonetheless, the roles of most of the $\beta$-defensins that are prevalently expressed in the epididymis are still unclear. Their contributions to the innate immunity of the reproductive tract as well as to sperm fertilisation abilities are questions that remain to be addressed.

Among the proteins characterized thus far in the epididymis, $\beta$-defensin 22, epididymal retinoic acid-binding protein, spermassociated antigen 11, cystatin 8 and transmembrane epididymal protein 1 are known for their high expression, at least at the transcriptional level. To date, the functions of sperm-associated antigen 11 have been revealed; it possesses antimicrobial effects on Escherichia coli and Candida albicans. In addition, sperm-associated antigen 11 binds to caput epididymal sperms and initiates their motility, ${ }^{11}$ thus endowing sperm-fertilizing ability. $\beta$-defensin 22 is the most promising candidate for similar functional investigations, considering that it is transcribed at a rate 28000 -fold higher in the epididymis than in other non-reproductive rat tissues. ${ }^{12}$ Rat $\beta$-defensin 22 was independently identified in different laboratories and is also known as '2D6 glycoprotein' or 'E-3 epididymal fluid protein'. ${ }^{13-15}$ Using the monoclonal antibody 2 D6, $\beta$-defensin 22 was localized in principal cells in the distal caput epididymis; immunoblotting also revealed its presence as a soluble high-molecular-weight complex in the secreted fluid from this epididymal region. ${ }^{13}$ Immunofluorescence localisation indicated the presence of $\beta$-defensin 22 on the entire sperm tail, although a lower intensity of $\beta$-defensin 22 is detected in the head of sperm from the corpus and cauda regions. ${ }^{15}$

Here, we report that a soluble recombinant protein of $\beta$-defensin 22 has antimicrobial and heparin-binding activities, which matches its possession of the defensin-like and lectin-like motifs. ${ }^{15}$ Because heparin contributes to sperm chemo-attraction, ${ }^{16,17}$ capacitation, ${ }^{18}$ acrosome reaction ${ }^{19}$ regulation of sperm-zona pellucida interactions and polyspermy, ${ }^{20}$ our findings suggest that $\beta$-defensin 22 might function not only in the innate immunity but also in sperm fertilisation abilities via its heparin-binding property.

\section{MATERIALS AND METHODS}

\section{Plasmids and strains}

pGEM-T Easy Vector Systems (Promega Corporation, Fitchburg, WI, USA) were utilized to clone the $\beta$-defensin 22 gene and the host was E. coli DH5a. A common plasmid, pET28a (Merck KGaA, Darmstadt, Germany), and host strain E. coli BL21 (DE3) were used to express recombinant protein. In order to test the antimicrobial activity of the recombinant peptide, E. coli K12D31, Staphylococcus aureus

${ }^{1}$ NPFPC Key Laboratory of Contraceptives and Devices, Shanghai Institute of Planned Parenthood Research, Shanghai 200032, China; ${ }^{2}$ Laboratory for Reproductive Biology, School of Life Science, University of Science and Technology of China, Hefei 230027, China; ${ }^{3}$ Shanghai Key Laboratory for Molecular Andrology, State Key Laboratory of Molecular Biology, Institute of Biochemistry and Cell Biology, Shanghai Institutes for Biological Sciences, Chinese Academy of Sciences, Shanghai 200031, China and ${ }^{4}$ Chronic Disease Program, Ottawa Hospital Research Institute, Ottawa, Ontario K1Y 4E9, Canada

* These authors contributed equally to this work.

Correspondence: Dr H Diao (diaohua77@hotmail.com) and Prof. Y L Zhang (ylzhang@sibs.ac.cn)

Received: 21 December 2009; Revised: 2 April 2010; Accepted: 14 July 2010; published online 13 December 2010 
CMCC 26003 and C. albicans SC5314 were used in assays of antimicrobial activity.

\section{Recombinant expression and purification of rat $\beta$-defensin 22}

The cDNA of rat $\beta$-defensin 22 was obtained according to a previous description. ${ }^{15}$ Primers (forward primer, $5^{\prime}$-ccccatgggcaactggtacgttcgaa-3'; reverse primer, 5' -ccctcgaggggtgcagcagtggtg-3') were synthesized to amplify the cDNA corresponding to the peptide from amino acids 21 to 111 (with no signal peptide). The underlined bases represent restriction sites designed in the primers. The amplified DNA fragment was digested with $\mathrm{NcoI}$ and $\mathrm{XhoI}$ and then inserted into pET28a. The ligation products were transformed to competent E. coli and the transformed clones were cultured in LB medium (Luria-Bertani broth) containing kanamycin $\left(50 \mu \mathrm{g} \mathrm{ml}^{-1}\right)$. The clones were analysed by PCR using the specific forward and reverse primers. The PCR products were analysed on agarose gels. One of the clones with specific amplification was sent to Invitrogen Co. (Shanghai, China) for sequencing (primed by the T7 promoter primer according to the manual of PET28). The whole insert and the $3^{\prime}$ sequence of the multiple cloning site were also sequenced in one reaction. All enzymes and kits used in the molecular cloning were from TaKaRa Biotechnology Co., Ltd (Dalian, China).

Recombinant plasmids were transformed to competent E. coli BL21 (DE3). Single colonies were inoculated to $3 \mathrm{ml} \mathrm{LB}$ medium containing $50 \mu \mathrm{g} \mathrm{ml}^{-1}$ kanamycin and cultured at $37^{\circ} \mathrm{C}$ with shaking. Overnight cultures were seeded in $200 \mathrm{ml} \mathrm{LB}$ medium containing kanamycin and cultured at $37^{\circ} \mathrm{C}$ at 250 revolutions per minute until the optical density at $600 \mathrm{~nm}$ reached 0.6. Protein expression was induced with 0.3 or $0.1 \mathrm{mmol}^{-1}$ isopropyl $\beta$-D-1-thiogalactopyranoside (IPTG) at $30{ }^{\circ} \mathrm{C}$ for $4 \mathrm{~h}$. Equal volumes of supernatants after sonication were loaded and analysed on 15\% sodium dodecyl sulphate-polyacrylamide gel electrophoresis (SDS-PAGE) gels. The harvested cells were sonicated in lysis buffer and the recombinant protein was purified using nickel-nitrilotriacetic acid (Ni-NTA) resin according to protocol 12 of the QIAexpress Kit manual (5th ed., QIAGEN Inc., Hilden, Germany). The purified protein was dialysed against $0.9 \% \mathrm{NaCl}$ solution on ice three times ( $1 \mathrm{~h}$ for each incubation). The concentration of the purified protein was measured using the BCA Protein Assay Kit (Thermo Scientific, Rockford, IL, USA). Purified samples were stored at $-20{ }^{\circ} \mathrm{C}$ until use.

\section{Mass spectroscopy analysis, acetic acid-urea (AU) PAGE, reducing and non-reducing SDS-PAGE analyses}

The recombinant protein defb 22 was digested with trypsin and all peptide fragments were chosen for sequencing by liquid chromatography-tandem mass spectrometry (LC-MS/MS) analysis in the Research Center for Proteome Analysis (Key Lab of Proteomics, Institute of Biochemistry and Cell Biology, Shanghai Institutes for Biological Sciences). LC-MS/MS experiments were performed with an LTQ linear ion trap mass spectrometer (Thermo Finnigan, San Jose, CA, USA) equipped with a microspray source. The LTQ mass spectrometer was operated in the data-dependent mode with full scan $\mathrm{m} / \mathrm{z}$ range $400-1800$. The LC-MS system was fully automated and was under the direct control of the Xcalibur software system (Thermo Finnigan). The 10 ions with the most intense signals in every full scan were automatically selected for MS/MS. The MS/MS data were searched against the database International Protein Index RAT v3.36 using the SEQUEST algorithm and protein identification criteria based on Charge +1 , Xcorr $\geqslant 1.9$; Charge +2 , Xcorr $\geqslant 2.2$; and Charge +3, Xcorr $\geqslant 3.75$, DelCN $\geqslant 0.1$.
The AU-PAGE gels consisted of $5.0 \mathrm{~mol} \mathrm{l}^{-1}$ urea, $16 \%$ polyacrylamide, $5 \%$ acetic acid, $0.2 \%(\mathrm{w} / \mathrm{v})$ ammonium persulphate and $0.5 \%$ (v/v) $N, N, N^{\prime}, N^{\prime}$-tetramethylethylenediamine. The AU-PAGE was run in $5 \%$ acetic acid at a constant mode of $300 \mathrm{~V}$. SDS-PAGE was similar to Laemmli's method ${ }^{21}$ and the gels were prepared using the BIO-RAD mini-gel apparatus (Bio-Rad Laboratories, Inc., Hercules, CA, USA). Samples were prepared by incubation of protein with loading buffers with or without $5 \%$ (v/v) $\beta$-mercaptoethanol at $37^{\circ} \mathrm{C}$ for $5 \mathrm{~h}$. The SDS-PAGE was run at a constant voltage of $110 \mathrm{~V}$. Gels were stained in staining solution containing $0.1 \%$ coomassie blue R-250, $30 \%(\mathrm{v} / \mathrm{v})$ ethanol and $10 \%(\mathrm{v} / \mathrm{v})$ acetic acid.

\section{Antimicrobial assays}

As most defensins show antimicrobial activity when tested under low ionic strength conditions, ${ }^{2}$ the purified $\beta$-defensin 22 was desalted by dialysis against $5 \%$ glycerol. Three common microbes (E. coli, C. albicans and S. aureus) were selected to detect the antimicrobial potency of the recombinant $\beta$-defensin 22 by colony-forming unit (CFU) assays. Antimicrobial activity assays against E. coli K12D31 and C. albicans SC5314 followed the protocols in our previous publication. ${ }^{22}$ The duration of incubation of the recombinant protein with each bacterial species was $3 \mathrm{~h}$. For S. aureus, the Mueller-Hinton broth with and without $1.5 \%$ agar was utilized. Overnight cultures were diluted to $10^{4}$ CFUs ml ${ }^{-1}$ using sterile buffer $\left(10 \mathrm{mmol} \mathrm{l}^{-1}\right.$ Tris- $\mathrm{HCl}$, $\mathrm{pH}$ 7.4). The other steps followed the protocol of anti-E. coli K12D31 assays. Surviving colonies were counted by hand, and antimicrobial activity was calculated using the following formula: \%survival= $100 \times($ number of colonies surviving from the treatment with $\beta$-defensins/number of colonies surviving from the treatment with control). All values were represented as means from at least three experiments. Further statistical analysis (analysis of variance) was performed using the SAS software system (SAS Institute Inc., Cary, NC, USA).

\section{Carbohydrate-binding ability}

The lectin-like motif of recombinant $\beta$-defensin 22 was verified by testing its affinity to carbohydrate beads since the lectin-like motif has carbohydrate-binding activity. Components of the Carbohydrate Gel Kit (CGK-series; EY Laboratories, Inc., San Mateo, CA, USA) containing $N$-acetylgalactosamine gel, mannose gel, $\alpha$-fucose gel and lactose gel were screened. In addition, heparin sepharose (GE Healthcare Bio-Sciences AB, Uppsala, Sweden) and chitin beads (New England Biolabs, Ltd, Beijing, China) were tested. The screening was based on the binding of recombinant $\beta$-defensin 22 to carbohydrate beads. Briefly, $100 \mu \mathrm{g}$ purified protein was added to $100 \mu \mathrm{l}$ beads in $10 \mathrm{mmol}^{-1}$ Tris-HCl, pH 7.4. After gentle shaking for $1 \mathrm{~h}$ at room temperature, the mixture was separated with a short spin and the beads were washed twice with $0.5 \mathrm{ml}$ buffer $\left(10 \mathrm{mmol} \mathrm{l}^{-1}\right.$ Tris- $\mathrm{HCl}$, $\mathrm{pH}$ 7.4). The beads were then added to $100 \mu$ l loading buffer and analysed on $15 \%$ SDS-PAGE gels. Alternatively, the $\beta$-defensin 22 bound on carbohydrate beads was eluted with buffers containing increasing concentrations of $\mathrm{NaCl}$ from 0.1 to $3.0 \mathrm{~mol}^{-1}$. The eluates were analysed on 15\% SDS-PAGE gels.

The specific binding of recombinant $\beta$-defensin 22 to heparin beads was further proved by adding competitive heparin and chondroitin sulphate A (Bio Basic Inc., Markham, Ontario, Canada) to the binding buffer. The working concentrations of heparin and chondroitin sulphate A were $0,0.1,0.4,0.8$ and $1.6 \mathrm{mg} \mathrm{ml}^{-1}$. The protein bound on beads was eluted with $10 \mathrm{mmol} \mathrm{l}^{-1}$ Tris- $\mathrm{HCl}(\mathrm{pH}$ 7.4) containing $1.0 \mathrm{moll}^{-1} \mathrm{NaCl}$. Bound and unbound protein fractions were analysed on $15 \%$ SDS-PAGE gels. 


\section{RESULTS}

\section{Soluble expression and antimicrobial activity of recombinant}

\section{$\boldsymbol{\beta}$-defensin 22}

There are three strategies to obtain the rat $\beta$-defensin 22 protein: collection from epididymal tissues, chemical synthesis or recombinant expression. Natural rat $\beta$-defensin 22 in the epididymis has a strong tendency to aggregate and bind tightly to the sperm plasma membrane. ${ }^{13}$ It is therefore difficult to purify this protein from the sperm membrane and luminal contents in mild solutions. Because chemical synthesis of $\beta$-defensins is expensive and success is limited, ${ }^{23}$ the use of recombinant expression strategies is preferred. ${ }^{24}$

Efficient soluble protein expression was important in the recombinant strategy of defensin synthesis, ${ }^{23}$ with soluble expression itself being the minimal requirement. The recombinant construct was confirmed by DNA sequencing covering the whole open-reading frame region and the bilateral sequences. Fortunately, the soluble form of recombinant $\beta$-defensin 22 was successfully expressed in the E. coli BL21 (DE3). Although the induction of $1.0 \mathrm{mmol}^{-1}$ IPTG produced higher amounts of $\beta$-defensin 22 peptide than that of $0.3 \mathrm{mmol} \mathrm{l}^{-1}$ IPTG, the amount of the soluble product remained equal in both induction conditions (Figure 1a). We therefore chose the $0.3 \mathrm{mmol}^{-1}$ IPTG concentration to induce recombinant $\beta$-defensin 22 production. The supernatant products were then purified by passage through Ni-NTA affinity columns. The recombinant $\beta$-defensin 22 was purified from the supernatant by using the Ni-NTA affinity chromatography as shown in Figure $1 \mathrm{~b}$. The purity of the recombinant protein was analysed by reducing and non-reducing SDS-PAGE (Figure 1c) and AU-PAGE (Figure 1d) as well. The band in the reducing SDS-PAGE had an apparent molecular weight higher than the calculated value of $10106.33 \mathrm{Da}$. One of the reasons for this might be the existence of odd cysteines. The free cysteine in the carboxyl region may have caused oligomerisation through intermolecular disulphide bridging. In the reducing SDS-PAGE, recombinant $\beta$-defensins 22 might tend to form artefact bands of dimers because cysteine oxidation of chemokines by ammonium persulphate during the stacking phase has been observed. ${ }^{25}$ In addition, the recombinant $\beta$-defensins 22 might have a strong tendency to form aggregates in the non-reducing SDS-PAGE analysis. Another finding of the AU-PAGE analysis was the persistence of a band at a higher molecular weight than the expected band despite different loading amounts. The bands with unexpected higher molecular weights and retardation on the top of gel might also consist of aggregated forms of the recombinant protein. Besides, some material that displayed retardation at the top of the gel was observed (Figure 1d). These proteins that seemed not to enter the gel might have consisted of insoluble aggregates.

Because no commercial antibody was available, the purified recombinant $\beta$-defensin 22 protein was digested with trypsin and identified by LC-MS/MS analysis. All fragments were chosen for sequencing and 12 unique peptide fragments $\left(\mathrm{MH}^{+}\right)$were identified. For clarity, only a mass spectrum profile of the largest fragment is shown in Figure 1e. Database searches (http://www.test.proteomecommons.org/dataset. jsp? $i=66770$ ) indicated that the most relevant result was a protein named 'Gene_Symbol = LOC171412 2D6 glycoprotein'. Because '2D6 glycoprotein' was the symbol for rat $\beta$-defensin 22 , this result confirmed that the protein was indeed rat $\beta$-defensin 22 .

Like other members of the $\beta$-defensin family, such as RBD1 and $\mathrm{rBin} 1 \mathrm{~b},{ }^{22}$ the recombinant $\beta$-defensin 22 was effective in the inhibition of E. coli and C. albicans in a dose-dependent manner (Figure 2), with statistical significance (one-way ANOVA and Duncan's multiple range test at the $5 \%$ level of significance; Table 1).
These data indicated that $\beta$-defensin 22 might prefer to inhibit Gramnegative microbes.

\section{Heparin-binding activity of recombinant $\boldsymbol{\beta}$-defensin 22}

To verify whether the putative lectin-like motif exists, the affinities of recombinant $\beta$-defensin 22 for carbohydrates such as $N$-acetylgalactosamine, mannose, $N$-acetylglucosamine, $\alpha$-fucose, lactose, heparin and chitin were screened. The purified protein predominantly bound to heparin beads and was eluted with $0.5-1.0 \mathrm{moll}^{-1} \mathrm{NaCl}$ solution as shown in Figure $3 \mathrm{a}$. The minimal $\mathrm{NaCl}$ concentration needed for elution was similar to those of other heparin-binding proteins; for example, RNase A and angiogenin were eluted at approximately $0.3-0.8 \mathrm{moll}^{-1} \mathrm{NaCl}^{26}{ }^{26}$ No other carbohydrate beads in the assay were found to have affinity for recombinant $\beta$-defensin 22 (data not shown). The specificity of this affinity for heparin was further confirmed by adding competitive heparin to the binding buffer before mixing. The amount of $\beta$-defensin 22 bound on heparin beads decreased with the increasing concentration of free heparin added. Concomitantly, the concentrations of free and heparin-binding forms of $\beta$-defensin 22 in the solution also increased. This result indicated that rat $\beta$-defensin 22 possesses the lectin-like motif, which can recognize heparin. To determine whether this affinity was merely based on the negative charges of the sulphate group, the affinity for heparin was determined with competitive free chondroitin sulphate-A, which also contains sulphate. A very weak competition effect was observed even at the concentration of $1.6 \mathrm{mg} \mathrm{ml}^{-1}$ chondroitin sulphate A as compared with heparin of the same concentration (Figure $3 \mathrm{c}$ ).

\section{DISCUSSION}

The major aims of this investigation were: (i) to determine whether rat $\beta$-defensin 22 acts as an antimicrobial peptide contributing to innate defence; and (ii) to ascertain whether the putative lectin-like motif in the protein is functional. If the carbohydrate ligands that match the lectin-like motif were found, this would shed light on the investigation of defensin-membrane interactions and the potent fertilizing functions of defensins.

Obtaining soluble expression of $\beta$-defensins is a challenging task. The method of intein-mediated fusion expression ${ }^{22}$ was successful in producing a soluble fusion protein of rat $\beta$-defensin 22 , but the tag could not be removed efficiently (data not shown). Therefore, we chose a traditional method to express the protein with His-tag as previously reported. ${ }^{15}$ In the SDS-PAGE analysis, the bands of $\sim 14$ and $\sim 30 \mathrm{kDa}$ we observed were also reported by other researchers, ${ }^{15}$ although their original data were omitted. The high tendency to aggregate might account for the altered migration of proteins in the SDS-PAGE and AU-PAGE analyses. The material that could not enter the AU-PAGE gel might have consisted of insoluble aggregates, because the recombinant protein has a high tendency to form these structures. Defensins are broad-spectrum cationic antimicrobial peptides that exist in various organisms. ${ }^{27}$ Yenugu et al. ${ }^{28}$ had shown that the antibacterial potencies of the His-tag-removed HE2 proteins ( $\beta$-defensin HE2) were similar to those of their His-tagged counterparts. To our knowledge, no antibacterial potency derived from Histag has been reported. However, there is the possibility that the His-tag reduces the antibacterial potency of $\beta$-defensin 22 . His-tagged recombinant rat $\beta$-defensin 22 caused only a $73 \%$ reduction in $E$. coli CFU with a 3 -h exposure, whereas HE2 $\beta 1$ peptide caused a $90 \%$ reduction in CFU after incubation for $10 \mathrm{~min}$ at $25 \mu \mathrm{g} \mathrm{ml}^{-1}\left(2.65 \mu \mathrm{mol} \mathrm{l}^{-1}\right)$. Other untagged $\beta$-defensins, $\mathrm{rBin} 1 \mathrm{~b}$ and $\mathrm{hBD} 2,{ }^{22}$ with the same 3 -h exposure and assay protocols, also caused a more than $90 \%$ reduction 


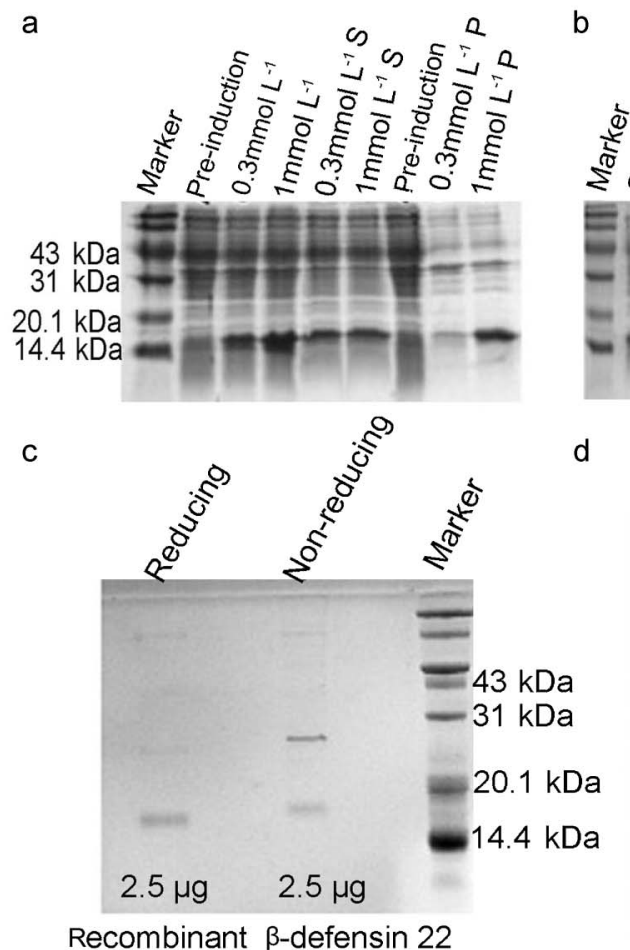

e

Dta: 008050221B_YHG_2.8897.8897.2 Precursor mass: $\overline{1080} .81$ Mass type: Average Mod's : $\quad\left(M^{*}+15.9994\right) \quad \mathrm{C}=160.1652$

Ion series for charge: +1

\begin{tabular}{lcc} 
AA A ions & B ions & Y ions \\
\hline L & 114.17 & - \\
A & 185.24 & 2048.05 \\
G & 242.30 & 1976.97 \\
Q & 370.43 & 1919.92 \\
C & 530.59 & 1791.79 \\
G & 587.64 & 1631.62 \\
G & 644.69 & 1574.57 \\
A & 715.77 & 1517.52 \\
D & 830.86 & 1446.44 \\
G & 887.91 & 1331.35 \\
N & 1002.01 & 1274.30 \\
Q \\
A & 1130.14 & 1160.20 \\
A \\
A & 1201.22 & 1032.07 \\
A & 1272.30 & 960.99 \\
G & 1343.38 & 889.91 \\
T & 1400.43 & 818.84 \\
Q & 1501.54 & 761.78 \\
A & 1629.66 & 660.68 \\
A & 1700.74 & 532.55 \\
G & 1771.82 & 461.47 \\
G & 1828.87 & 390.39 \\
T & 1885.92 & 333.34 \\
R & 1987.03 & 276.29 \\
\hline & & 175.19
\end{tabular}

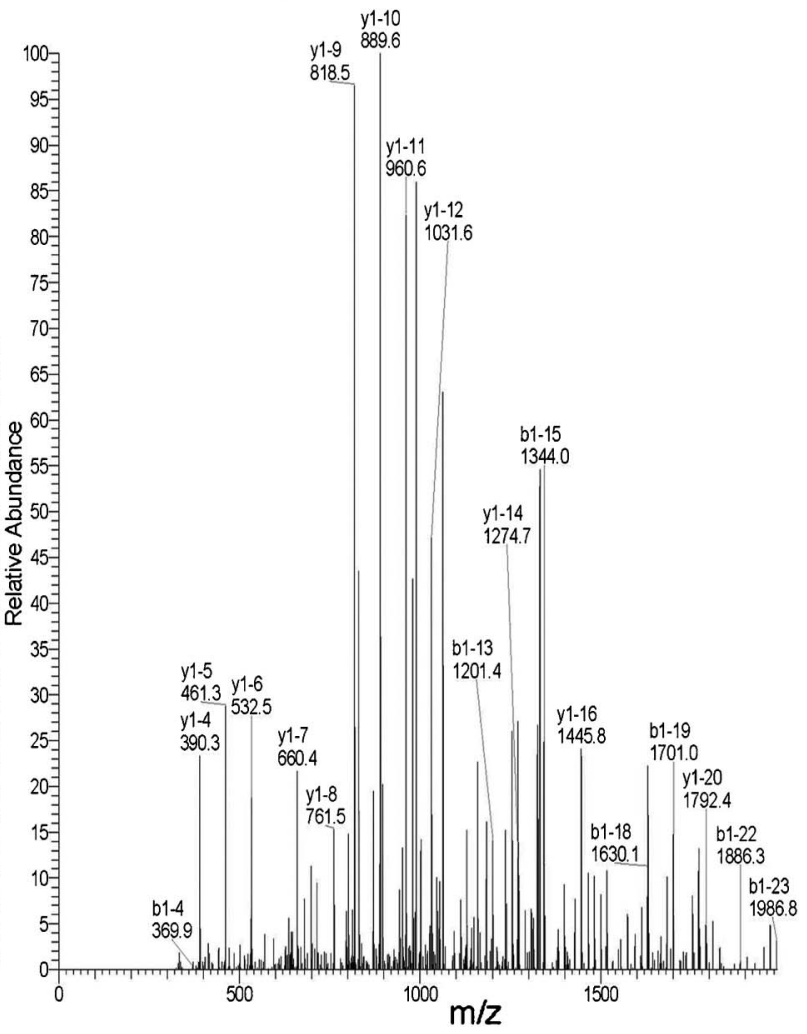

Figure 1 The recombinant expression (a), purification (b) and identification of rat recombinant $\beta$-defensin 22 (c-e). The cells before and after induction with varying concentrations of IPTG were analysed on 15\% SDS-PAGE to optimize the expression conditions (a). 'S' represents the supernatant of the cell lysate after centrifugation. 'P' represents the pellet of cell lysate after centrifugation. The rat recombinant $\beta$-defensin 22 was purified using Ni-NTA affinity chromatography and analysed on $15 \%$ SDS-PAGE gels (b). 'Wash 1-5' and 'eluate 1-3' represents the collections of serial aliquots in the process of wash and elution. The purity of recombinant protein was then confirmed by 15\% SDS-PAGE (c) and 16\% acetic acid-urea-PAGE (d). 'Reducing' and 'non-reducing' represent recombinant $\beta$-defensin 22 treated with loading buffers containing and not containing $5 \%(\mathrm{v} / \mathrm{v}) \beta$-mercaptoethanol respectively. (e) Identification of the recombinant protein by LC-MS/MS analysis. A representative MS profile of an ion and its amino acid sequence were shown in (e). IPTG, isopropyl $\beta$-D-1-thiogalactopyranoside; LC-MS/MS, liquid chromatography-tandem mass spectrometry; Ni-NTA, nickel-nitrilotriacetic acid; SDS-PAGE, sodium dodecyl sulphate-polyacrylamide gel electrophoresis. 


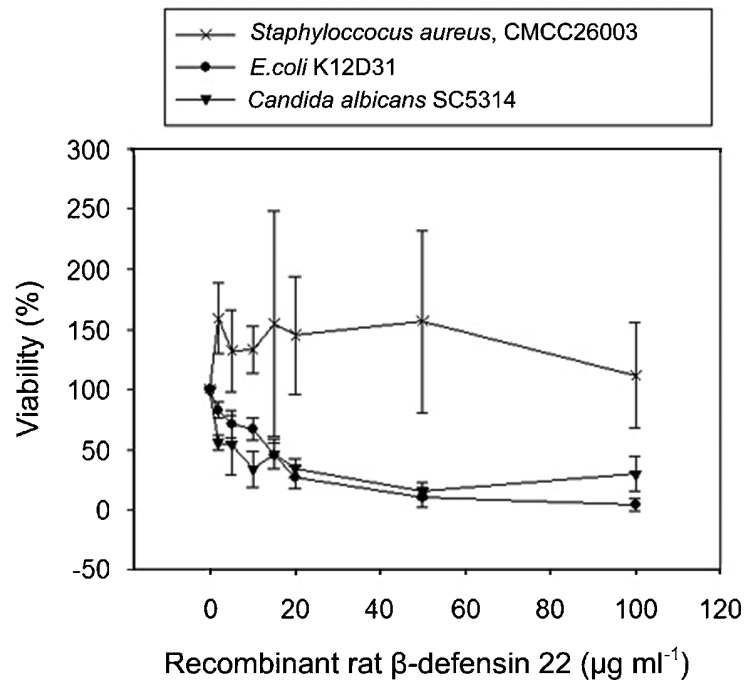

Figure 2 The antimicrobial activity of recombinant $\beta$-defensin 22 was determined with CFU assays. Triplicate assays were performed and the viabilities of three strains that represent $\mathrm{G}^{-}, \mathrm{G}^{+}$and fungi pathogens are shown. The data were also analysed using one-way ANOVA and Duncan's multiple range test at the $5 \%$ level of significance $(P<0.05)$ in Table 1 . The bars indicate standard deviation. $\mathrm{CFU}$, colony-forming units; $\mathrm{G}^{-}$, Gram-negative; $\mathrm{G}^{+}$, Gram-positive.

in CFU after incubation for $3 \mathrm{~h}$ at $20 \mu \mathrm{g} \mathrm{ml}^{-1}$. Notably, ESC42, ESP13.2 and $\beta$-defensin 22 share a C-terminal domain that is absent from any true $\beta$-defensin; hence, they may form a small subfamily. ${ }^{13}$ ESC42 shows more antibacterial potency than the His-tagged $\beta$-defen$\sin 22$ for the same 3-h incubation with E. coli. ${ }^{29}$ The C-terminal Histag might reduce the antibacterial potency of $\beta$-defensin 22 , although the physiological significance of the long C-terminal domain remains unclear.

The survival of Candida appeared to increase at higher doses of the recombinant peptide. The reason for this might be that proteins of relatively high concentration might tend to aggregate and decrease the effective amounts of free molecules. Thus, the survival of microbes increased at higher doses of the recombinant peptide in the test of antiCandida activity. But in the case of E. coli, the survival did not tend to increase at the same dosages. This implies that the protein might have higher affinity for the cell membranes of E. coli. The high affinity might

Table 1 The viability data of Escherichia coli and Candida albicans exposed to recombinant protein $\boldsymbol{\beta}$-defensin 22 were analysed using one-way ANOVA and Duncan's multiple range test at the $5 \%$ level of significance

\begin{tabular}{lll}
\hline \multirow{2}{*}{$\begin{array}{l}\text { Recombinant } \beta \text {-defensin } \\
22\left(\mu \mathrm{g} \mathrm{m} l^{-1}\right)\end{array}$} & \multicolumn{2}{l}{ Viability, means $\pm S D^{\mathrm{a}}(\%)$} \\
\cline { 2 - 3 } & E. coli K12D31 & C. albicans SC5314 \\
\hline 0 & $100^{\mathrm{b}}$ & $100^{\mathrm{b}}$ \\
2 & $83.0 \pm 6.4^{\mathrm{c}}$ & $56.2 \pm 5.9^{\mathrm{c}}$ \\
5 & $71.6 \pm 11.6^{\mathrm{c}, \mathrm{d}}$ & $54.3 \pm 24.6^{\mathrm{c}, \mathrm{d}}$ \\
10 & $67.1 \pm 9.3^{\mathrm{d}}$ & $33.8 \pm 14.8^{\mathrm{c}, \mathrm{d}, \mathrm{e}}$ \\
15 & $45.4 \pm 10.8^{\mathrm{e}}$ & $46.3 \pm 12.3^{\mathrm{c}, \mathrm{d}}$ \\
20 & $27.4 \pm 9.1^{\mathrm{f}}$ & $34.5 \pm 7.6^{\mathrm{c}, \mathrm{d}, \mathrm{e}}$ \\
50 & $10.5 \pm 8.3^{\mathrm{g}}$ & $15.8 \pm 6.7^{\mathrm{e}}$ \\
100 & $4.2 \pm 5.0^{\mathrm{g}}$ & $30.3 \pm 14.8^{\mathrm{d}, \mathrm{e}}$ \\
\hline
\end{tabular}

${ }^{a}$ Means \pm SD denotes the means of triplicate values with standard deviation (SD). Means with the same letter are not significantly different at $P \geqslant 0.05$.

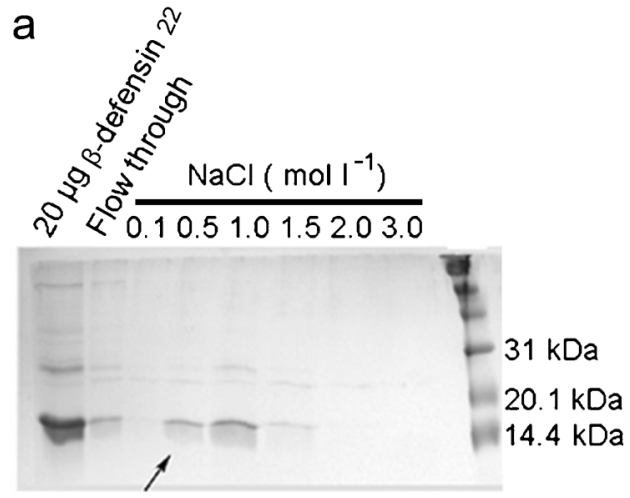

b

Heparin $0 \quad 0.10 .40 .8 \quad 1.6 \quad 1.6\left(\mathrm{mg} \mathrm{ml}^{-1}\right)$ $\beta$-defensin $22+++++$

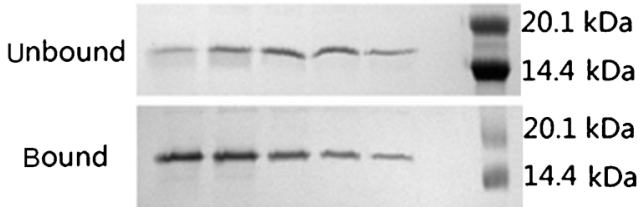

C

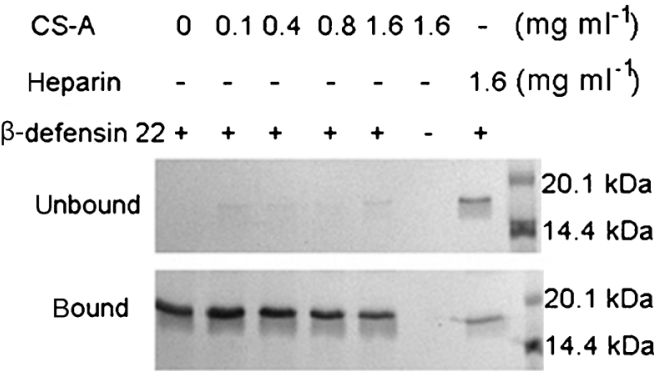

Figure 3 The specific affinity of recombinant rat $\beta$-defensin 22 for heparin beads. Recombinant $\beta$-defensin $22(100 \mu \mathrm{g})$ bound on heparin beads $(100 \mu \mathrm{l})$ was eluted with elution buffer containing varying concentrations of $\mathrm{NaCl}$ and analysed on a $15 \%$ SDS-PAGE gel (a). Arrow indicates the band of recombinant protein eluted with minimal $\mathrm{NaCl}$ concentration. The purified rat $\beta$-defensin 22 with addition of either free heparin (b) or free chondroitin sulphate (c) was incubated with heparin beads. The unbound protein and the eluate of the heparin beads (bound) were analysed on 15\% SDS-PAGE. '+' represents the addition of equal amount of rat $\beta$-defensin 22 to the incubation system at a working concentration of $0.8 \mathrm{mg} \mathrm{ml}^{-1}$. '-' indicates the addition of an equal volume of binding buffer. SDS-PAGE, sodium dodecyl sulphate-polyacrylamide gel electrophoresis.

cause depletion of free monomers and prevention of intermolecular aggregation.

The natural rat $\beta$-defensin 22 can exist in a series of molecular weights including 20,24, 28 and $32 \mathrm{kDa}$, which are the various weights reported in different publications, but all of which indicated that the natural protein was a glycoprotein. ${ }^{13,15}$ According to a well-accepted theory, charge and hydrophobicity of $\beta$-defensins are the most important factors ${ }^{23}$ for antimicrobial activity. Whether the glycosylated rat $\beta$-defensin 22 retains antimicrobial activity needs further investigation. However, the tight binding of rat $\beta$-defensin 22 to membrane (in an unknown but not glycosylphosphatidylinositol-anchored manner $)^{13}$ makes the protein difficult to isolate in a soluble and active form.

The carbohydrate affinity of rat $\beta$-defensin 22 was evaluated through screening of carbohydrate-conjugated beads and was 
confirmed with competition assays. The defensin-like motif and lectin-like motif, rather than charges, were the main sources of affinity because the similar sulphated polysaccharide chondroitin sulphate-A had no competitive impact on the affinity of rat $\beta$-defensin 22 for heparin beads. On the other hand, heparin-binding peptides ${ }^{30}$ and many other lectins exerted direct antimicrobial activity. ${ }^{31-33}$ It was obvious that there could be overlaps between defensins and lectins considering that both of them belong to large protein families with versatile functions. As only weak sensitivity of recombinant rat $\beta$-defensin 22 to $150 \mathrm{mmol}^{-1} \mathrm{NaCl}$ and $1.6 \mathrm{mg} \mathrm{ml}^{-1}$ heparin was observed (data not shown), the antimicrobial activity associated with the recombinant protein may not be associated with the defensin motif.

The sperm localisation of rat $\beta$-defensin $22,{ }^{15}$ and the affinity for heparin might suggest a role for the protein in fertility. Heparin is a functional molecule in the male reproductive system. In mammals, heparin was reported to be an important factor that contributes to sperm chemo-attraction and capacitation. ${ }^{16-19}$ In addition, heparin and heparin-like molecules, for example, glycosamineglycan-sulphates (GAGs), were able to induce decondensation of intact spermatozoan nuclei and regulate polyspermy in vitro. ${ }^{20,34,35}$ Heparin binding-site density might be related to the ability of human spermatozoa to successfully undergo the acrosome reaction. ${ }^{36}$ Heparin has also been hypothesized to stabilize the zona pellucida system (tesistance to pronase) through binding to oviduct-specific glycoprotein. There was possibility that rat $\beta$-defensin 22 had affinity for other GAGs. As GAGs had effects on the signal pathway of rat gametes, ${ }^{37}$ rat $\beta$-defensin 22 might also have roles in fertilisation through binding GAGs.

The association between heparin and cationic defensins has also been reported by other researchers. ${ }^{38}$ The interaction of heparin with defensins appears to be involved in a protective mechanism that is responsible for regulating both the anticoagulation activity of heparin and the inhibition activity of non-enzymatic fibrinolysis of defensin. ${ }^{38}$ Considering the characteristics of rat $\beta$-defensin 22 , the soluble form of the protein in the epididymal lumen might act as a protective factor by neutralizing heparin or GAGs, which were produced in high abundance close to the sites of infection. ${ }^{39}$

As at least fivefold more rat $\beta$-defensin 22 antigen was detected on the sperm membrane than in the secretions, ${ }^{14}$ the rat $\beta$-defensin 22 recruited by the sperm membrane might be the predominant form. Two possible mechanisms for the association of rat $\beta$-defensin 22 with the sperm membrane could be suggested: one based on the heparinlectin interactions in order to anchor the protein on the membrane, and the other based on protein-lipid interactions. The first one seemed less likely because: (i) the binding was resistant to $4 \mathrm{~mol}^{-1}$ urea, $1 \mathrm{moll}^{-1} \mathrm{KCl}$ and other reagents, ${ }^{13}$ whereas the rat $\beta$-defensin 22 could be eluted from heparin beads at $0.5-1.0 \mathrm{~mol}^{-1}$ salt concentration; and (ii) the binding was resistant to the solubilisation of phosphatidylinositol-specific phospholipase C. Some detailed observations supported the second mechanism: (i) the membrane-bound rat $\beta$-defensin 22 presented approximately similar properties in the aqueous and triton X-114 layers if treated with triton X-114; and (ii) the plasma membrane of the sperm tail, where $\beta$-defensin 22 bound, had approximately fivefold slower lipid diffusion than it did when bound on the sperm head. ${ }^{40}$ The possible mechanism for the association between rat $\beta$-defensin 22 and cell membrane might be through tight protein-lipid interaction.

Recently, a mouse DEFB22 protein bound on the whole surface of sperm was reported to be a major component of the mouse sperm glycocalyx. ${ }^{41}$ But there was no obvious homology between mouse DEFB22 and rat $\beta$-defensin 22 except conserved cysteine pairing and the position of the defensin domain. Considering the high glycosylation of natural rat $\beta$-defensin 22 , this protein might also act as a component of the rat sperm glycocalyx. The major mechanism of the association between sperm and rat $\beta$-defensin 22 might be based on protein-lipid interactions and thus facilitate sperm glycocalyx formation.

Taken together, this is the first report that confirms the antimicrobial activity and heparin-binding function of recombinant $\beta$-defensin 22. This research provides new information on the functions of rat $\beta$-defensin 22 in both innate immunity and fertilisation. Because the functions of a number of $\beta$-defensins in mammals are unclear, this research widens the scope of investigation on $\beta$-defensins.

\section{AUTHOR CONTRIBUTIONS}

Hua Diao conceived the original idea, designed the study and carried out the experiments in Figures 2 and 3. He also prepared the original manuscript. Heguo Yu designed and carried out the experiments in Figure 1. He provided the critical protein samples of $\beta$-defensin 22 for this study. Fei Sun did the project planning. Yonglian Zhang supervised the project and edited the manuscript. Nongnuj Tanphaichitr performed part of the data analysis, provided professional advice and edited part of the manuscript.

\section{COMPETING FINANCIAL INTERESTS}

The authors declare no competing financial interests.

\section{ACKNOWLEDGMENTS}

We are grateful to Dr Hongxing Zhao of the Shanghai Institute of Planned Parenthood Research for his technical assistance in statistical analysis. This work was supported by the National Basic Research Program of China (973 Program, 2009CB941702).

1 Jones R. Plasma membrane structure and remodelling during sperm maturation in the epididymis. J Reprod Fertil Supp/ 1998; 53: 73-84.

2 Ganz T. Defensins: antimicrobial peptides of innate immunity. Nat Rev Immunol 2003; 3: 710-20.

3 Sun CQ, Arnold R, Fernandez-Golarz C, Parrish AB, Almekinder T et al. Human betadefensin-1, a potential chromosome 8p tumor suppressor: control of transcription and induction of apoptosis in renal cell carcinoma. Cancer Res 2006; 66: 8542-9.

4 Steinstraesser L, Oezdogan Y, Wang SC, Steinau HU. Host defense peptides in burns. Burns 2004; 30: 619-27.

5 Conejo-Garcia JR, Benencia F, Courreges MC, Kang E, Mohamed-Hadley A et al. Tumor-infiltrating dendritic cell precursors recruited by a beta-defensin contribute to vasculogenesis under the influence of Vegf-A. Nat Med 2004; 10: 950-8.

6 Dacheux JL, Gatti JL, Dacheux F. Contribution of epididymal secretory proteins for spermatozoa maturation. Microsc Res Tech 2003; 61: 7-17.

7 Lehrer RI, Ganz T. Defensins of vertebrate animals. Curr Opin Immuno/2002; 14: 96102.

8 Yang D, Chertov O, Bykovskaia SN, Chen Q, Buffo MJ et al. Beta-defensins: linking innate and adaptive immunity through dendritic and T cell CCR6. Science 1999; 286: $525-8$

9 Ganz T, Oren A, Lehrer RI. Defensins: microbicidal and cytotoxic peptides of mammalian host defense cells. Med Microbiol Immunol (Berl) 1992; 181: 99-105.

10 Pazgier M, Hoover DM, Yang D, Lu W, Lubkowski J. Human beta-defensins. Cell Mol Life Sci 2006; 63: 1294-313.

11 Zhou CX, Zhang YL, Xiao L, Zheng M, Leung KM et al. An epididymis-specific betadefensin is important for the initiation of sperm maturation. Nat Cell Biol 2004; 6: 458-64.

12 Johnston DS, Turner TT, Finger JN, Owtscharuk TL, Kopf GS et al. Identification of epididymis-specific transcripts in the mouse and rat by transcriptional profiling. Asian J Androl 2007; 9: 522-7.

13 Zanich A, Pascall JC, Jones R. Secreted epididymal glycoprotein 2D6 that binds to the sperm's plasma membrane is a member of the beta-defensin superfamily of poreforming glycopeptides. Biol Reprod 2003; 69: 1831-42. 
14 Jones R, Brown CR. Identification and characterization of the 2D6 and Mr 23,000 antigens on the plasma membrane of rat spermatozoa. Biochem J 1987; 241: 353 60.

15 Rao J, Herr JC, Reddi PP, Wolkowicz MJ, Bush LA et al. Cloning and characterization of a novel sperm-associated isoantigen (E-3) with defensin- and lectin-like motifs expressed in rat epididymis. Biol Reprod 2003; 68: 290-301.

16 Sliwa L. Effect of heparin on human spermatozoa migration in vitro. Arch Androl 1993; 30: 177-81.

17 Sliwa L. Heparin as a chemoattractant for mouse spermatozoa. Arch Androl 1993; 31 149-52.

18 Valencia A, Wens MA, Merchant H, Reyes R, Delgado NM. Capacitation of human spermatozoa by heparin. Arch Androl 1984; 12 Suppl: 109-13.

19 Parrish JJ, Susko-Parrish JL, First NL. Effect of heparin and chondroitin sulfate on the acrosome reaction and fertility of bovine sperm in vitro. Theriogenology 1985; 24: 537-49.

20 Coy P, Canovas S, Mondejar I, Saavedra MD, Romar R et al. Oviduct-specific glycoprotein and heparin modulate sperm-zona pellucida interaction during fertilization and contribute to the control of polyspermy. Proc Natl Acad Sci USA 2008; 105: 15809-14.

21 Laemmli UK. Cleavage of structural proteins during the assembly of the head of bacteriophage T4. Nature 1970; 227: 680-5

22 Diao H, Guo C, Lin D, Zhang Y. Intein-mediated expression is an effective approach in the study of beta-defensins. Biochem Biophys Res Commun 2007; 357: 840-6.

23 Kluver E, Adermann K, Schulz A. Synthesis and structure-activity relationship of betadefensins, multi-functional peptides of the immune system. J Pept Sci 2006; 12 . 243-57.

24 Chen H, Xu Z, Peng L, Fang X, Yin X et al. Recent advances in the research and development of human defensins. Peptides 2006; 27: 931-40.

25 Crow MK, Karasavvas N, Sarris AH. Protein aggregation mediated by cysteine oxidation during the stacking phase of discontinuous buffer SDS-PAGE. Biotechniques 2001; 30: 311-6.

26 Soncin F, Strydom DJ, Shapiro R. Interaction of heparin with human angiogenin. J Biol Chem 1997; 272: 9818-24.

27 Wong JH, Xia L, Ng TB. A review of defensins of diverse origins. Curr Protein Pept Sci 2007; 8: 446-59.

28 Yenugu S, Hamil KG, Birse CE, Ruben SM, French FS et al. Antibacterial properties of the sperm-binding proteins and peptides of human epididymis 2 (HE2) family; salt sensitivity, structural dependence and their interaction with outer and cytoplasmic membranes of Escherichia coli. Biochem J 2003; 372: 473-83.

29 Yenugu S, Hamil KG, Radhakrishnan Y, French FS, Hall SH. The androgen-regulated epididymal sperm-binding protein, human beta-defensin 118 (DEFB118) (formerly ESC42), is an antimicrobial beta-defensin. Endocrinology 2004; 145: 3165-73.

30 Andersson E, Rydengard V, Sonesson A, Morgelin M, Bjorck L et al. Antimicrobia activities of heparin-binding peptides. Eur J Biochem 2004; 271: 1219-26.

31 Mukherjee S, Partch CL, Lehotzky RE, Whitham CV, Chu H et al. Regulation of C-type lectin antimicrobial activity by a flexible N-terminal prosegment. J Biol Chem 2009 284: 4881-8.

32 Zhao ZY, Yin ZX, Xu XP, Weng SP, Rao XY et al. A novel C-type lectin from the shrimp Litopenaeus vannamei possesses anti-white spot syndrome virus activity. J Virol 2009; 83: 347-56.

33 Yu Y, Huang H, Feng K, Pan M, Yuan S et al. A short-form C-type lectin from amphioxus acts as a direct microbial killing protein via interaction with peptidoglycan and glucan. J Immunol 2007; 179: 8425-34.

34 Delgado NM, Reyes R, Huacuja L, Carranco A, Merchant H et al. Decondensation of human sperm nuclei by glycosamineglycan-sulfate from sea urchin egg. $J$ Exp Zool 1982; 224: 457-60.

35 Coy $\mathrm{P}$, Aviles $\mathrm{M}$. What controls polyspermy in mammals, the oviduct or the oocyte? Biol Rev Camb Philos Soc 2010; 85: 593-605.

36 Lalich RA, Vedantham S, McCormick N, Wagner C, Prins GS. Relationship between heparin binding characteristics and ability of human spermatozoa to penetrate hamster ova. J Reprod Fertil 1989; 86: 297-302.

37 Borg N, Holland M. The effect of glycosaminoglycans on rat gametes in vitro and the associated signal pathway. Reproduction 2008; 135: 311-9.

38 Liapina LA, Kondashevskaia MV, Kokriakov VN, Shamova OV. Interaction of heparin with defensin, a nonenzymatic cationic protein from neutrophils. Vopr Med Khim 1992; 38: 39-42.

39 Menozzi FD, Pethe K, Bifani P, Soncin F, Brennan MJ et al. Enhanced bacteria virulence through exploitation of host glycosaminoglycans. Mol Microbiol 2002; 43: 1379-86.

40 Wolfe CA, James PS, Mackie AR, Ladha S, Jones R. Regionalized lipid diffusion in the plasma membrane of mammalian spermatozoa. Biol Reprod 1998; 59: 1506-14.

41 Yudin Al, Tollner TL, Treece CA, Kays R, Cherr GN et al. Beta-defensin 22 is a major component of the mouse sperm glycocalyx. Reproduction 2008; 136: 753-65. 